\title{
A Study of the Cumulative Impact Forces of Stainless-Steel Reinforced Concrete Pier
}

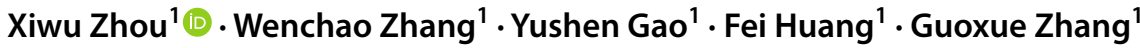

Received: 30 October 2018 / Accepted: 1 August 2019 / Published online: 8 August 2019

(C) The Author(s) 2019

\begin{abstract}
Stainless-steel reinforcement is used to replace the common reinforcement of RC pier in the marine environment, so as to solve the corrosion issue of reinforcement. According to the collision force of stainless-steel reinforced concrete bridge pier under cumulative impact, in this paper the cumulative impact loss factors of the pier is considered to analyze the relationship between the pier stiffness and ultrasonic sound velocity by numerical simulation. The calculation formula of the collision force considering the cumulative impact damage of the pier is then created with the experimental verification and comparative analysis of relevant norms. The results show that the formula of the collision force proposed in this paper is able to better reflect the actual force of the cumulative impact of the pier.
\end{abstract}

Keywords Stainless-steel reinforcement $\cdot$ Ship-bridge cumulative collisions $\cdot$ Collision forces $\cdot$ Damage coefficient

\section{Introduction}

The frequent occurrence of bridge collision accidents leads to significant safety hazards and economic losses. The use of stainless steel reinforced materials in the construction of marine environmental bridges is able to effectively solve the structural durability issues caused by steel corrosion, and has thus become a new trend in bridge structure design (Wang et al. 2010; Zhang et al. 2017; Zhou et al. 2018). In practice, the phenomenon of pier service with impact damage is common. A key issue is the evaluation of the impact force when considering the cumulative impact damage of bridge piers.

Stainless-steel reinforcements of pier have shown superiority in strength, ductility, corrosion resistance, and maintenance costs (Yuan et al. 2011). Therefore, the use of the stainless-steel instead of common steel bars for marine environments has become the main development trend for solving the durability problems of pier. Many previous studies have confirmed that stainless-steel materials have more effective practical properties (Sarno et al. 2003, 2006, 2008). The current research results regarding the

Xiwu Zhou

1396209615@qq.com

http://www.fosu.edu.cn/

1 Foshan University, No. 18 Jiangwan Road, Chancheng District, Foshan 528000, Guangdong, China corrosion resistance of stainless-steel reinforced concrete have revealed that the corrosion resistance of stainless-steel reinforced concrete is somewhat higher than that of ordinary reinforced concrete (Gao et al.2018; Deng et al. 2014; Garcia-Alonso et al. 2007). In the studies conducted by Mohammad et al. (2013), Zhou et al. (2008), it was proven that stainless-steel materials had superior energy dissipation performances, anti-fatigue damage performances, and ductility Zhang et al. $(2017,2018$.) replaced the ordinary reinforcement in the piers with a stainless steel reinforcement uniform section, indicating that the ductility of stainless steel bars is favorable. Zhou et al. (2018) further studied the use of stainless-steel reinforcement uniform strength to replace ordinary reinforcement, so as to resolve the corrosion issue of the longitudinal reinforcement of the pier in the marine environment.

At present, the research methods involving pier collision force mainly include the formula method and numerical simulation method, while the traditional empirical formulas mainly include the Woisin formula (1976) and Pedersen formula (1991). The normative formulas mainly include the basic norm of Chinese railway bridge and culvert design (2005), general norm of China highway bridge and culvert design (2004), general norm of US highway bridge design (1993), and European norm formulas (1998). For the study of numerical simulation, Liu and Gu (2001), Hu et al. (2005) obtained the peak data of the collision force of the pier under different 
impact conditions; Consolazio and Cowan (2003) analyzed the influence of pier size and shape on the impact force, and Sha and Hao (2012) established an empirical formula for the peak impact force of bridge collision. However, for both the formula method and numerical simulation method, the research is based on the first collision condition of the bridge pier, without considering that the bridge structure is subjected to multiple collisions, which is not suitable for the calculation of cumulative multiple impacts.

In this research study, the characteristics of ship-bridge collision force formulas, in both domestic and international standards, were analyzed. Then, under the conditions of ship-bridge cumulative collisions, analysis and deduction processes were conducted based on the energy conservation, with consideration given to the damage status of the bridge pier. Meanwhile, a numerical analysis method was used to study the sizes of the ship-bridge collision forces and pier damages. A collision force calculation formula for the stainless-steel reinforced concrete bridge piers was then proposed under the condition of cumulative impact effects.

\section{Establishment of the Damage Collision Force Formula}

\subsection{Analysis of the Collision Force Formula}

This study's model of the ship-bridge collision process was analyzed based on the principle of energy conservation, as shown in Fig. 1. The stiffness coefficients of the pier and ship were set are $K_{1}$ and $K_{2}$ respectively; $\mathrm{m}$ is the boat mass; $\mathrm{v}$ is the velocity of the boat impact; $\mathrm{F}$ is the collision force of impact, $\Delta$; and $\delta$ is the deformation shift of the pier and ship. In other words, the moment the ship collided with the bridge pier, the following relationship was satisfied:

$E=\frac{1}{2} m v^{2}=\int_{0}^{\Delta} K_{1} x d x+\int_{0}^{\delta} K_{2} x d x=\frac{1}{2} K_{1} \Delta^{2}+\frac{1}{2} K_{2} \delta^{2}$

$K_{1} \Delta=K_{2} \delta=F$

Fig. 1 Ship-bridge collision diagram

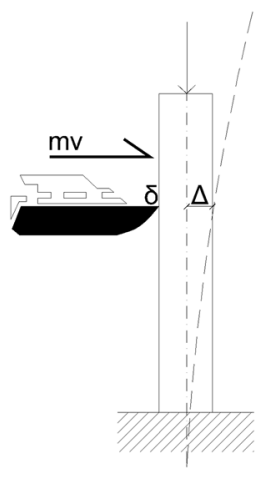

According to $\Delta=\frac{F}{K_{1}}$ and $\delta=\frac{F}{K_{2}}$, the collision force calculation formula could be obtained as follows:

$F=V \sqrt{\frac{\mathrm{m}}{\frac{1}{K} 1+\frac{1}{K} 2}}$

The impact force [as shown in Eq. (4)] in China's Railway Bridge and Culvert Code (2005) was found to be relatively consistent with Eq. (3), in which such influence factors as kinetic energy reduction and impact angles were considered:

$F=\gamma v \sin \alpha \sqrt{\frac{W}{C_{1}+C_{2}}}$

In the equation, $C_{1}$ and $C_{2}$ represent the elastic deformation coefficients of the ship and sub-structure, respectively; $\gamma$ is the kinetic energy reduction coefficient $\left(s / m^{2}\right) ; v$ denotes the impact velocity $(\mathrm{m} / \mathrm{s})$; and $W$ is the ship weight $(\mathrm{KN})$.

Then, by considering the applicability and normalization of impact force formula in China's Railway Bridge and Culvert Code, Eq. (4) was taken in this study as the basic formula for the impact force formula of the stainless-steel reinforced concrete bridge pier undergoing the working conditions of cumulative impact damages.

\subsection{Damage Analysis Based on Ultrasonic Wave Velocity}

By referring to China's Railway Bridge and Culvert Code, it was found that the deformation coefficient $C$ of the pier and ship materials was not specified in detail, and the given reference range was excessively general. Therefore, the deformation coefficient $C_{2}$ of the bridge pier was analyzed in this study following the pier collision, and the existing damages were found to cause changes in the $C_{2}$. Then, the damage coefficient was introduced to further describe the damages to the bridge pier (Chen 2014; Kachanov 1958).

The research results indicated that the ultrasonic wave velocity in the material was closely related to the elastic modulus and other properties. Following the damages to the material, the elastic modulus was observed to change, as was the ultrasonic propagation velocity (Zhang and Zhang 2001; Xu 2000; Qian and Zhou 1989). Therefore, the changes in the wave velocity could be used to define the material damage variables, and further judge the material damage situations. The specific formula was as follows:

$D=1-\frac{V_{b}^{2}}{V_{0}^{2}}$

In the equation, $V_{0}$ is the wave velocity before damages occurred $(\mathrm{m} / \mathrm{s})$; and $V_{b}$ is the wave velocity after damages occurred $(\mathrm{m} / \mathrm{s})$. 


\subsection{Relationship Between Stiffness and Ultrasonic Wave Velocity}

Following ship-bridge collisions, the damages to the pier will affect the impact forces of the re-collisions. Therefore, since the elastic modulus $\mathrm{E}$ of the pier will change after damages have occurred, the stiffness $\mathrm{K}$ and elastic modulus $\mathrm{E}$ will satisfy the linear function relationship as follows (Xu 2000):

$K=f(E)$

In this study's damage testing process of the bridge pier using an ultrasonic nondestructive technique, the function relationship between the wave velocity and elastic modulus could be expressed using the following equation (Zhang and Zhang 2001):

$E=\rho V^{2}$

In the equation, $V$ is the ultrasonic wave velocity $(\mathrm{m} / \mathrm{s})$; and $\rho$ is the concrete material density $\left(\mathrm{kg} / \mathrm{m}^{3}\right)$.

Then, by combining the above mentioned relationships, it was found that the linear function relationship between the elastic deformation coefficient $K$ of the bridge pier and the ultrasonic wave velocity square $V^{2}$ was satisfied.

In order to further examine the collision force calculation of the bridge pier after damages had occurred, the finite element general software ABAQUS was used for this study's numerical simulation. During the modeling process, the relationship between the damage coefficient $\mathrm{D}$ and the size of the collision force could be analyzed by changing the elastic deformation coefficient of the pier model.

During the creating process of the ship-bridge collision model, the numerical analysis process must be consistent with the actual situation. The selection of the concrete constitutive model is very important. In the next numerical simulation, the concrete damage plasticity model is selected for numerical modeling analysis (Zhang and Liu 2011). The elastic modulus values of concrete of different strength grades are shown in Table 1.

For the constitutive aspect of reinforcement, the plastic follow-up strengthening model is adopted in the model (Wang). The model has a good simulation effect considering the strain rate of the material and its failure. The stress-strain relationship is as follows, and the model parameters of the reinforcement material are shown in Table 2.

$\sigma_{y}=\sigma_{0}\left[1+\left(\frac{\bar{\varepsilon}}{C}\right)^{\frac{1}{p}}\right]\left(\sigma_{0}+\beta E_{p} \varepsilon_{p}^{e f f}\right)$

$\sigma_{0}$ —initial yield stress; $\bar{\varepsilon}$-strain rate; $C, P$-strain parameter; $\varepsilon_{p}^{e f f}$ —effective plastic strain; $E_{p}$ - plastic hardening modulus; $\beta$-hardening parameter. The test pier design parameters and Comparison of test values and formula values are shown in Table 3, 4.

$E_{p}=\frac{E_{\mathrm{tan}} E}{E-E_{\mathrm{tan}}}$

Table 1 Elasticity modulus of the concrete

\begin{tabular}{llllll}
\hline $\begin{array}{l}\text { Concrete } \\
\text { strength grade }\end{array}$ & C20 & C25 & C30 & C35 & C40 \\
\hline $\mathrm{N} / \mathrm{mm}^{2}$ & $2.55 \times 104$ & $2.80 \times 104$ & $3.00 \times 104$ & $3.15 \times 104$ & $3.25 \times 104$ \\
\hline
\end{tabular}

Table 2 Reinforcement material parameter

\begin{tabular}{lllllll}
\hline $\begin{array}{l}\text { Elasticity modulus } \\
\left(\mathrm{N} / \mathrm{mm}^{2}\right)\end{array}$ & Density & Poisson ratio & $\begin{array}{l}\text { Yield strength of } \\
\text { longitudinal rein- } \\
\text { forcement } \\
\left(\mathrm{N} / \mathrm{mm}^{2}\right)\end{array}$ & $\begin{array}{l}\text { Yield strength of } \\
\text { the stirrups } \\
\left(\mathrm{N} / \mathrm{mm}^{2}\right)\end{array}$ & Failure strain & Strain parameter $C$ Strain parameter $P$ \\
\hline $2.0 \times 10^{11}$ & $7.8 \times 10^{13}$ & 0.3 & $3.5 \times 10^{8}$ & $2.5 \times 10^{8}$ & 0.3 & 40 \\
\hline
\end{tabular}

Table 3 Test pier design parameters

\begin{tabular}{llllll}
\hline Specimen number & $\begin{array}{l}\text { Longitudinal } \\
\text { reinforcement } \\
\text { number }\end{array}$ & $\begin{array}{l}\text { Longitudinal rein- } \\
\text { forcement diameter } \\
(\mathrm{mm})\end{array}$ & $\begin{array}{l}\text { Stirrup } \\
\begin{array}{l}\text { Concrete } \\
\text { strength } \\
\text { grade }\end{array}\end{array}$ & $\begin{array}{l}\text { Section rein- } \\
\text { forcement ratio } \\
(\%)\end{array}$ \\
\hline M1-12 & 10 & 12 & $\Phi 8 @ 50$ & C40 & 1.25 \\
M1-20A & 6 & 20 & $\Phi 8 @ 50$ & C40 & 2.08 \\
M1-16 & 10 & 16 & $\Phi 8 @ 50$ & C40 & 2.21 \\
M1-20B & 8 & 20 & $\Phi 8 @ 50$ & C40 & 2.77 \\
M1-20 & 10 & 20 & $\Phi 8 @ 50$ & C40 & 3.46 \\
\hline
\end{tabular}


Table 4 Comparison of test values and formula values

\begin{tabular}{|c|c|c|c|c|c|}
\hline \multirow[t]{2}{*}{ Specimen no } & \multirow{2}{*}{$\begin{array}{l}\text { Average sound } \\
\text { velocity }(\mathrm{m} / \mathrm{s})\end{array}$} & \multirow{2}{*}{$\begin{array}{l}\text { Impact veloc- } \\
\text { ity }(\mathrm{m} / \mathrm{s})\end{array}$} & \multicolumn{2}{|c|}{ Impact force $\mathrm{F}(\mathrm{MN})$} & \multirow{2}{*}{$\begin{array}{l}\text { Relative } \\
\text { error (MN) } \\
(\%)\end{array}$} \\
\hline & & & Test values & Formula values & \\
\hline \multirow[t]{4}{*}{ M1-12 } & 4.235 & 1.3 & 0.09744763 & 0.119951816 & 18.76 \\
\hline & 4.183 & 1.88 & 0.15713983 & 0.171731414 & 8.50 \\
\hline & 4.162 & 2.79 & 0.23670471 & 0.254734272 & 7.08 \\
\hline & 4.161 & 3.72 & 0.31266027 & 0.32799325 & 4.67 \\
\hline \multirow[t]{4}{*}{ M1-20A } & 4.276 & 1.17 & 0.09457573 & 0.111571972 & 15.23 \\
\hline & 4.273 & 2.12 & 0.1812089 & 0.199335838 & 9.09 \\
\hline & 4.243 & 2.71 & 0.22765641 & 0.249791765 & 8.86 \\
\hline & 4.201 & 3.28 & 0.27908421 & 0.29262277 & 4.63 \\
\hline \multirow[t]{4}{*}{ M1-16 } & 4.189 & 1.22 & 0.09332549 & 0.114133031 & 18.23 \\
\hline & 4.162 & 2.12 & 0.19192635 & 0.192408878 & 0.25 \\
\hline & 4.126 & 2.75 & 0.23540086 & 0.246451353 & 4.48 \\
\hline & 4.100 & 3.35 & 0.26986594 & 0.29584513 & 8.78 \\
\hline \multirow[t]{4}{*}{ M1-20B } & 4.209 & 1.16 & 0.08918221 & 0.108183154 & 17.56 \\
\hline & 4.209 & 2.12 & 0.18490354 & 0.19771404 & 6.48 \\
\hline & 4.163 & 2.44 & 0.20848062 & 0.227557669 & 8.38 \\
\hline & 4.118 & 3.3 & 0.28708083 & 0.307762421 & 6.72 \\
\hline \multirow[t]{4}{*}{ M1-20 } & 4.176 & 0.87 & 0.06802684 & 0.081778537 & 16.82 \\
\hline & 4.172 & 2.19 & 0.18965968 & 0.205856318 & 7.87 \\
\hline & 4.138 & 2.71 & 0.24156185 & 0.254735443 & 5.17 \\
\hline & 4.047 & 3.18 & 0.28524404 & 0.298914653 & 4.57 \\
\hline
\end{tabular}

For the connection of steel and concrete parts, separate modeling is applied in this paper, which considers the interaction between concrete and steel. Although the steps in the modeling are relatively complicated, it is more favorable for simulating the state under actual conditions. A fixed constraint boundary condition was used to simulate the connection form between the bottom cap and foundation of the bridge pier. A uniformly distributed load was applied to the pier top to simulate the load effects of the bridge body on the pier. Meanwhile, the freedom degrees of a simulated small ship in every direction (with the exception of the $\mathrm{X}$-axis) were restricted. In addition, an analysis step was set in the $\mathrm{X}$-axis direction in order to achieve the impact speed of a small ship. The regularity and refinement of the grid division were found to be conducive to the improved accuracy of the calculation results, as shown in Fig. 2.

Figure 3 is the stress nephogram of the bridge pier during the collision process. It can be seen that the high stress areas are mainly concentrated in the local area of the contact surface and the bottom of the pier body.

In this study, by analyzing and processing the results of the numerical simulation, the collision force curve could be obtained, as shown in Figs. 4 and 5.

In accordance with the above relationship curve maps, a linear relationship between the load and deformation of the pier was assumed, where $C_{2}$ represents the elastic deformation coefficient of the pier, and $F$ represents the
Fig. 2 Stress nephogram: a Application effects of the boundary conditions; b Grid partitioning effects

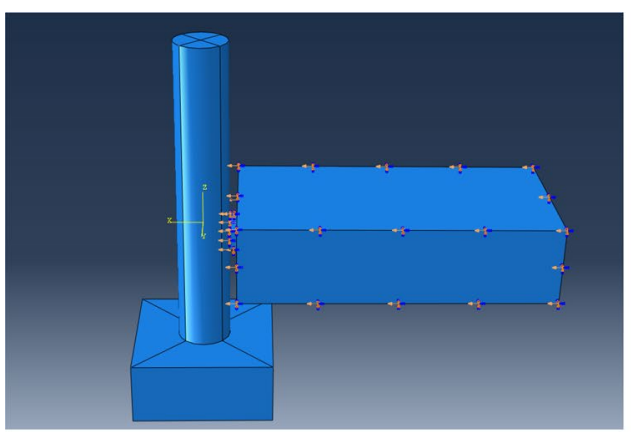

(a) Application effects of the boundary conditions;

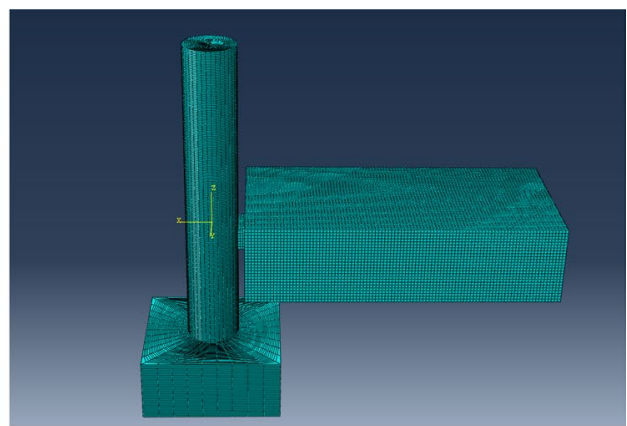

(b) Grid partitioning effects 
Fig. 3 Numerical analysis model: $\mathbf{a} \mathrm{T}=0.06 \mathrm{~s}$, impact frontal stress nephogram; $\mathbf{b}$ $\mathrm{T}=0.06 \mathrm{~s}$, impact back stress nephogram
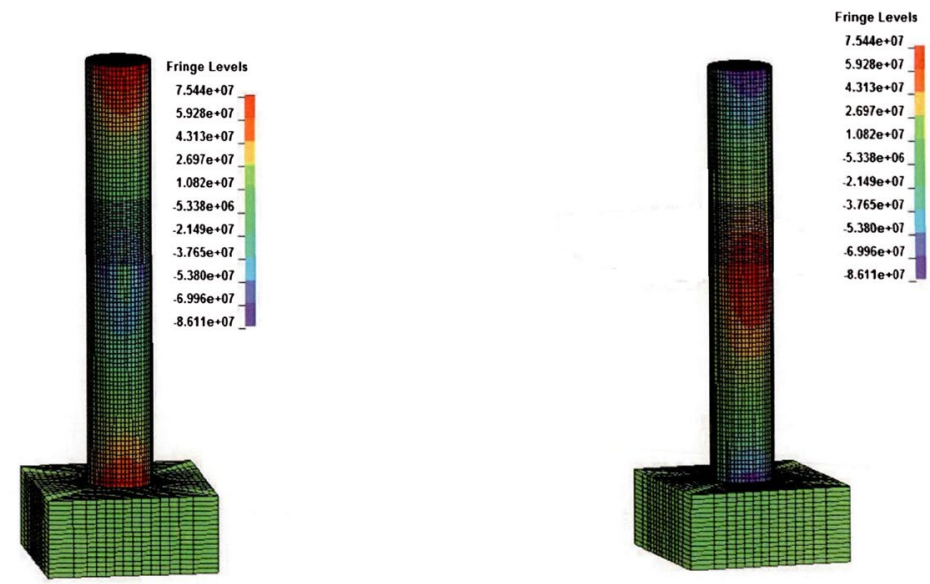

(a) $\mathrm{T}=\mathbf{0 . 0 6} \mathrm{s}$, impact frontal stress nephogram; (b) $\mathrm{T}=0.06 \mathrm{~s}$, impact back stress nephogram

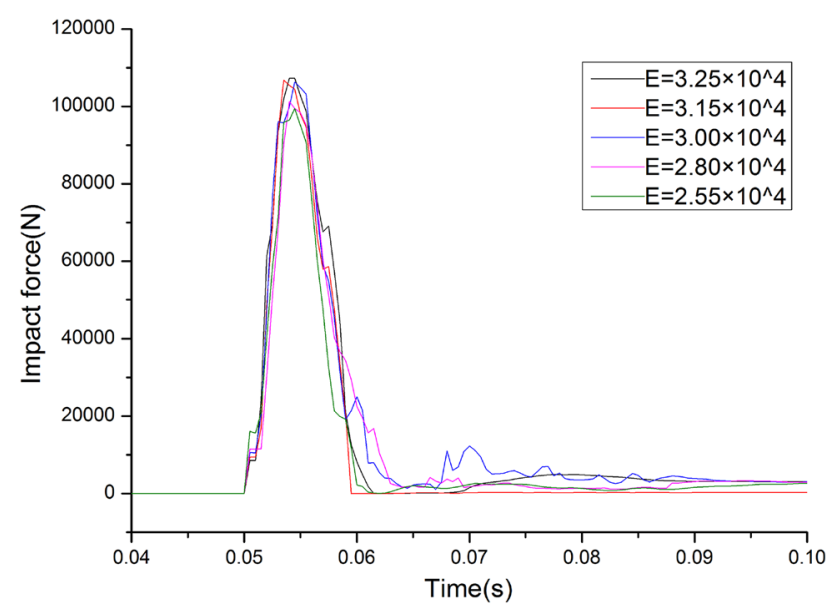

Fig. 4 F-E curve

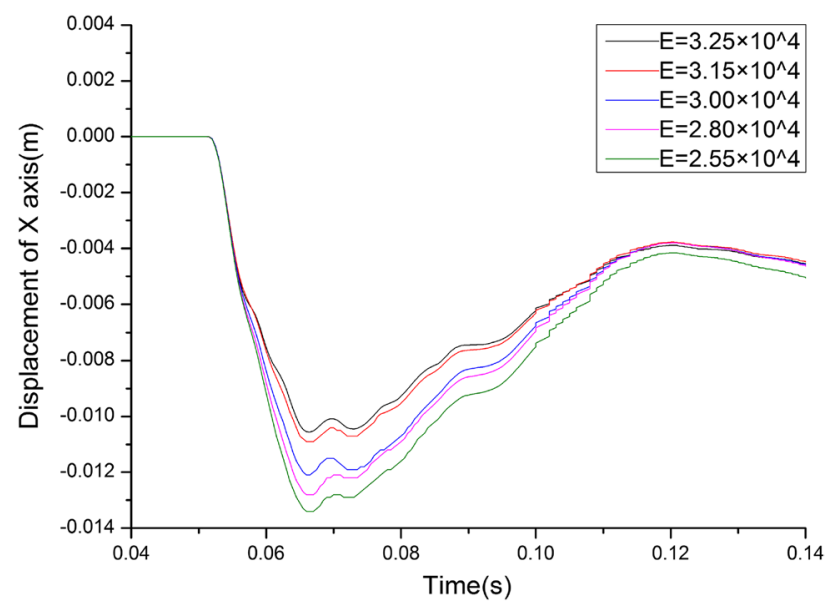

Fig. $5 \Delta-\mathrm{E}$ curve

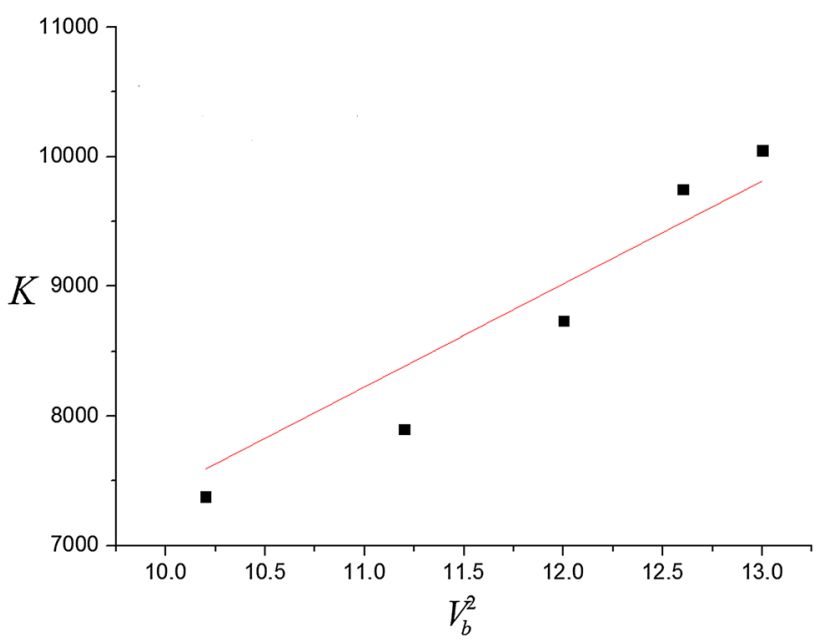

Fig. $6 K_{2}-V_{b}^{2}$ relationship curve

impact force. Then, the relative total displacement of the collision point along the normal velocity direction was represented by $\Delta$, and the relationship was expressed as follows:

$\Delta=F C_{2}$

The ultrasonic wave velocity square $V_{b}^{2}$ and pier stiffness $K$ were drawn in the same curve map in this study. It was found that the distribution of the scatter data indicated an obvious linear relationship. An OriginPro software fitting analysis was able to achieve better effect, as shown in Fig. 6.

The numerical simulation data of the ship-bridge collision indicated that the ultrasonic wave velocity square $V_{b}^{2}$ and pier stiffness coefficient $\mathrm{K}$ conformed better to a linear relationship, and this curve was observed to almost approach the origin. Therefore, $K=a V_{b}^{2}$ between $K$ and $V_{b}^{2}$ could be successfully obtained. 


\subsection{Collision Force Formula}

Through the above analysis, it could be seen that $K$ and $V_{b}^{2}$ satisfied $K=a V_{b}^{2}$. Also, the arbitrary $K_{2}^{\prime}$ and $V^{\prime 2}$ were able to satisfy the following formula:

$K_{2}^{\prime}=\frac{V^{\prime 2}}{V^{2}} K_{2}$

In the formula of China's Railway Bridge and Culvert Code, $C_{2}$ is denoted as the elastic deformation coefficient of the pier body, and together with the stiffness coefficient $K$ of the pier, satisfy the linear function relationship as follows:

$K=\frac{1}{C}$

Due to the fact that damage factor $D=1-\frac{V_{b}^{2}}{V_{0}^{2}}$,

Then, $\quad C_{2}^{\prime}=\frac{1}{K_{2}^{\prime}}=\frac{1}{(1-D) K_{2}}=\frac{C_{2}}{(1-D)}$

Following the ship-bridge cumulative collision, it was determined that the collision force formula of the stainlesssteel reinforced concrete pier (considering damage factor $D$ ) could be obtained as follows:

$F=\gamma v \sin \alpha \sqrt{\frac{W}{C_{1}+\frac{C_{2}}{(1-D)}}}$

where $C_{1}$ and $C_{2}$ represent the elastic deformation coefficients of the ship and sub-structure, respectively; $v$ is the collision velocity; $\gamma$ denotes the kinetic energy reduction coefficient; $w$ is the ship weight $(\mathrm{KN})$; and $D$ represents the damage coefficient.

\section{Verification and Analysis of the Test Results}

\subsection{Test Process}

The pier model was design and constructed for this study's horizontal impact test, and the data results of the testing were analyzed in order to compare the coincidence degrees between the impact force obtained by multiple collisions of the pier specimen, and those which were calculated in this study. Meanwhile, a contrast analysis was also conducted with a code formula for the purpose of determining the applicability of the formula proposed in this study.

The impact test was carried out on stainless-steel reinforced concrete bridge piers with different reinforcement ratios using an advanced ultrahigh heavy hammer impact test system in China. The specific test process is shown in Fig. 7. The pier model was designed using actual engineered reinforced concrete piers as the prototypes for the test specimen, and was on a scale of 1:5. The pier model concrete was C40 concrete, and the longitudinal bar was constructed from S2304 two-phase stainless-steel produced by UGITECH Co (France).

The test loading device was a multi-function ultrahigh heavy hammer impact tester system, as shown in Fig. 7. Then, using attached wire rope, the dropping of the hammer drove the laterally-placed small ship model, which horizontally impacted the pier specimen along a fixed orbit.

\subsection{Result Analysis}

Figure 8 details this study's comparison in the time history curves of the collision forces collected by each test column during the collision test.

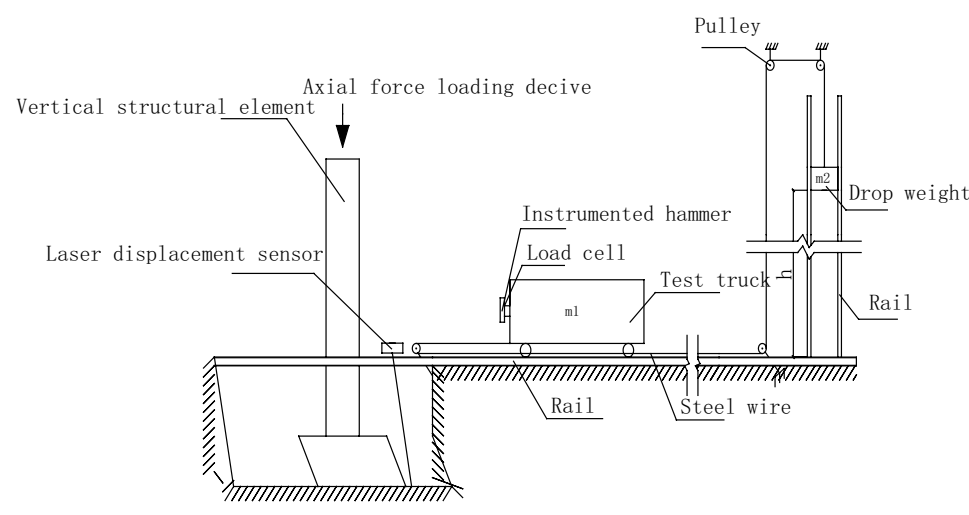

(a) Test model map;

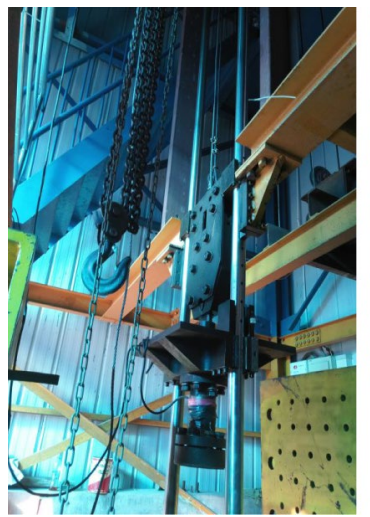

(b) Hammer tester;

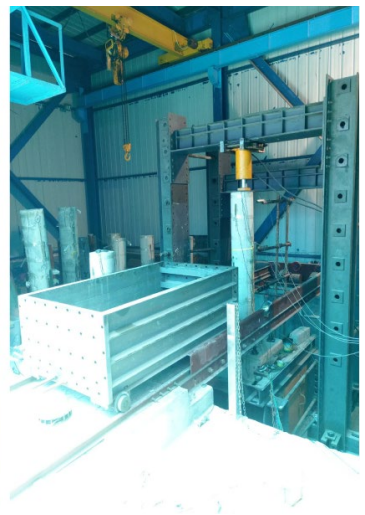

(c) Horizontal collusion system

Fig. 7 Multi-function ultrahigh heavy hammer impact test system: a Test model map; b Hammer tester; c Horizontal collusion system 

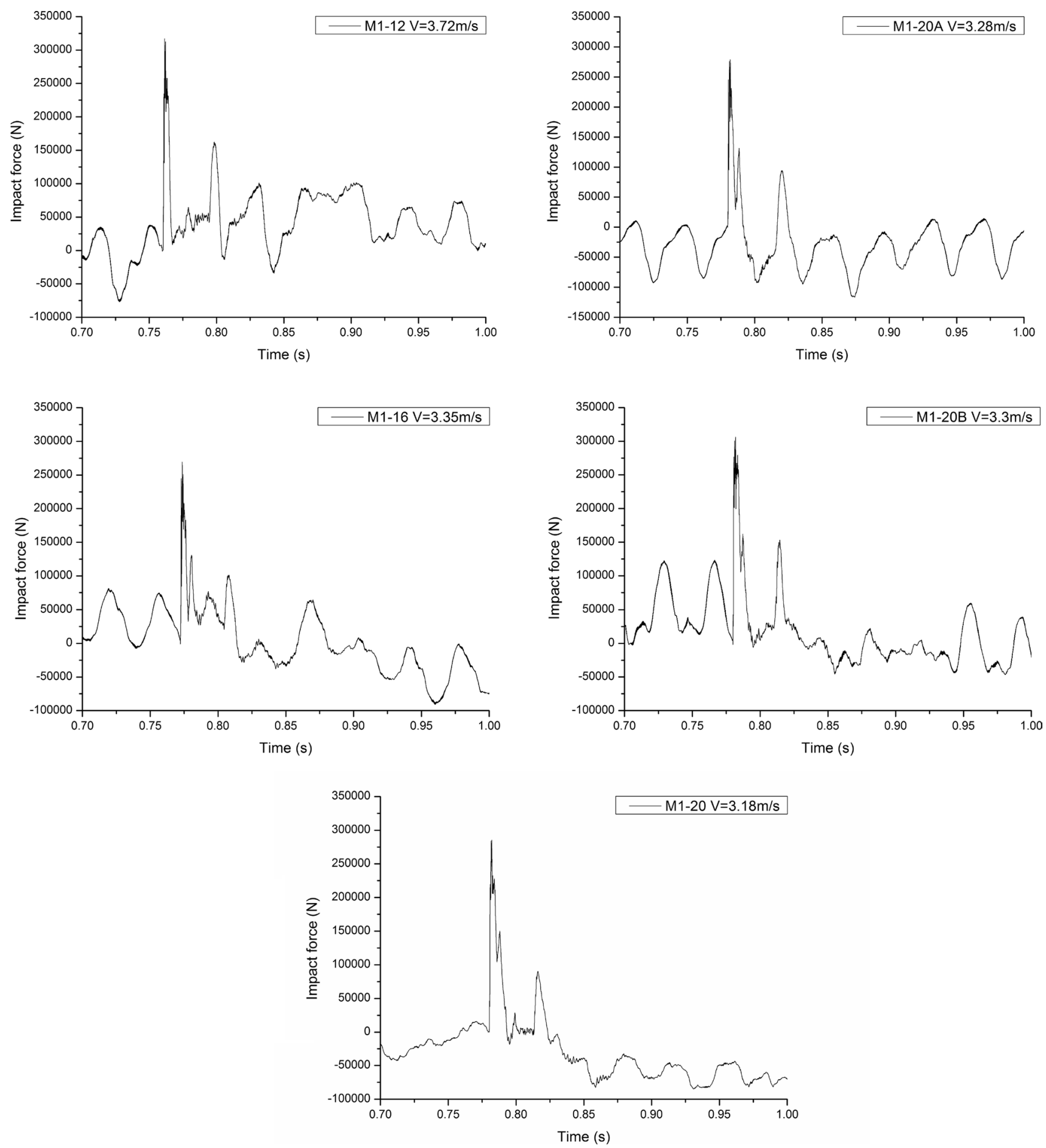

Fig. 8 Time history curves of the impact forces

The test data of the stainless-steel specimens were compared with the results of the collision force formula, as shown in the chart below.

Through the data in the above table, it could be seen that the formula calculation results obtained in this study had approached the test results with the relative change rate being mostly within $10 \%$, and with only a small overall gap observed. Therefore, when the stainless-steel bridge piers underwent cumulative impacts, and with consideration given to the pier damages, it was confirmed that the calculation formula of the collision force proposed in this study could effectively reflect the size of the impact forces during the 


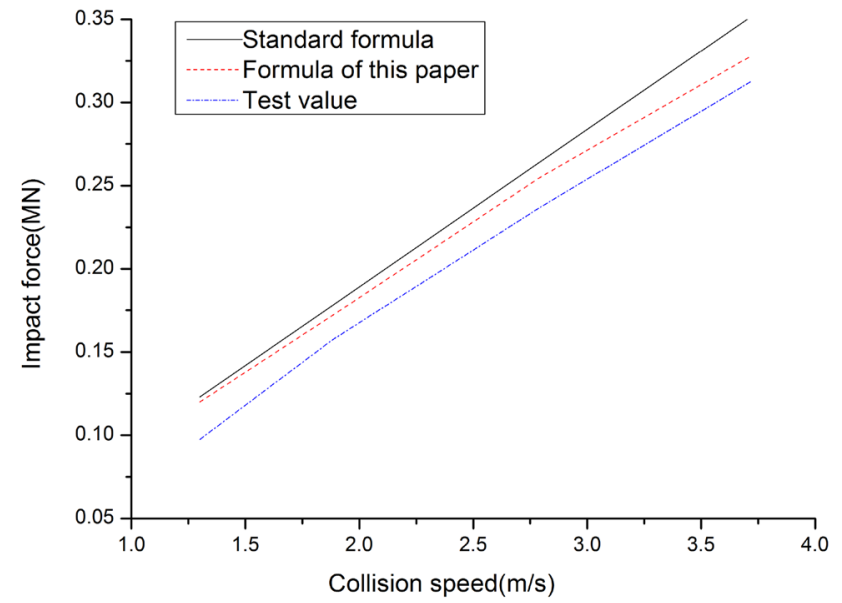

(a) $\mathrm{M} 1-12$

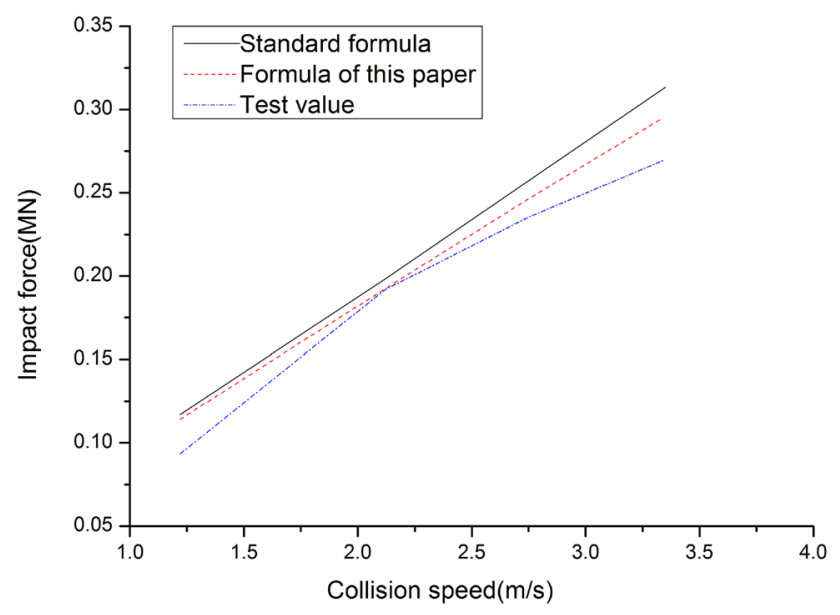

(c) M1-16

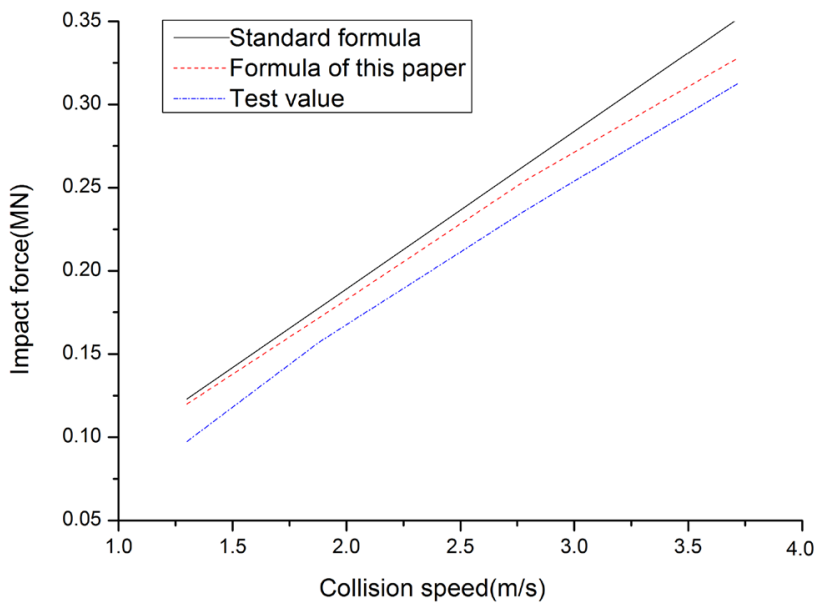

(b) M1-20A

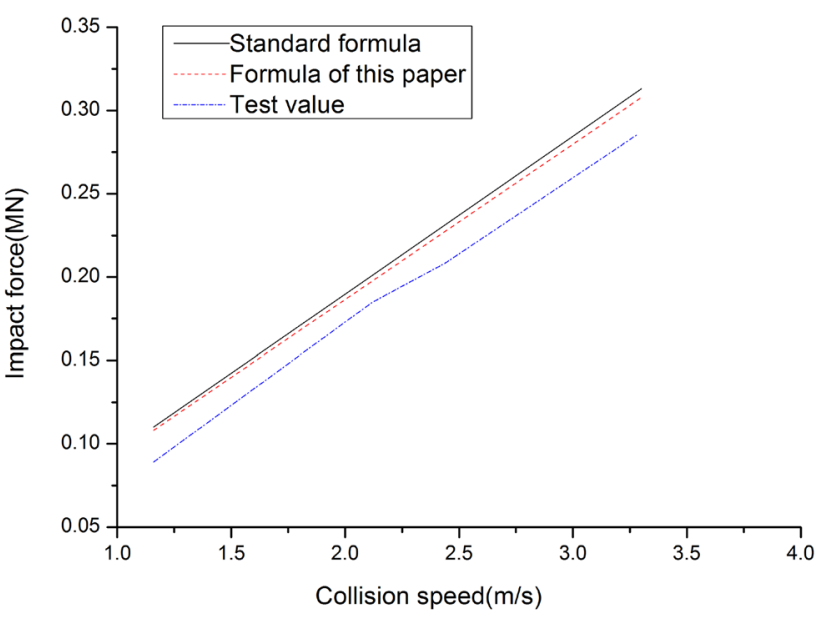

(d) M1-20B

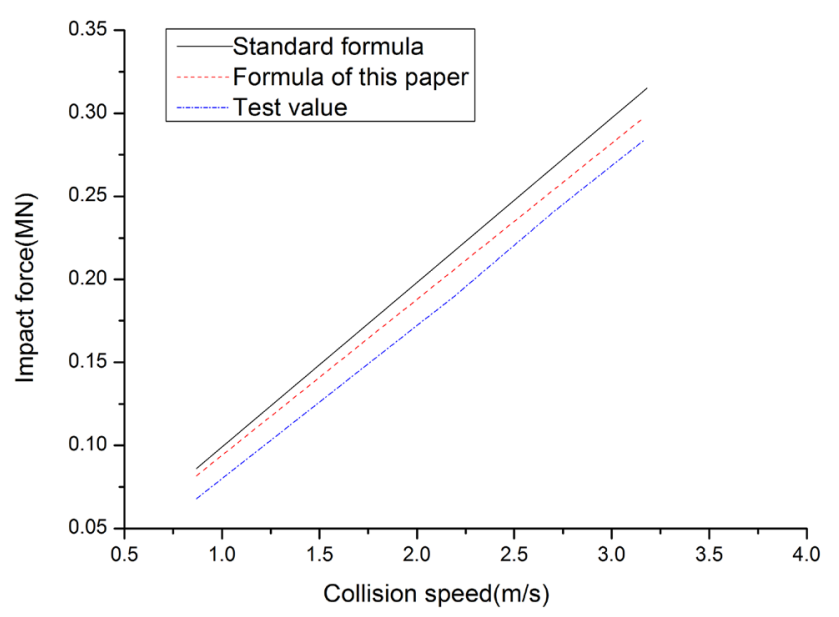

(e) M1-20

Fig. 9 Impact force comparison of derivation formula, code formula and test results 
collision occurrences with a certain applicable value. This result can be used to evaluate the damage of the pier and guide the actual engineering application such as repair and reinforcement of the pier.

The formula presented in this study was compared with the code formula and test results, and the results were drawn in the same curve diagram, as shown in Fig. 9.

In accordance with the above mentioned figures, it was confirmed that after stainless-steel reinforced concrete piers underwent multiple cumulative collisions, the influences of the damages to the pier structures on the size of the impact force tended to increase. When compared with the results of the code formula, the formula proposed in this study had considered the effects of the damage factors. With the accumulation of the impact damages, it was found that the differences had tended to increase. Also, the higher the damage degree of the pier was, the more accurately this study's formula reflected the size of the actual impact force would be. Furthermore, when compared with the code formula, the formula curve in this study was found to be more consistent with the test curve, and thus could better reflect the impact force situation of the stainless-steel reinforced concrete bridge pier following the collision damages.

\section{Conclusions}

In this paper, according to the collision force of stainless steel reinforced concrete bridge piers under cumulative impact, the relationship between the pier stiffness and ultrasonic sound velocity under the cumulative damage of the pier is analyzed by the numerical simulation method. The calculation formula of collision force of the stainless steel reinforced concrete pier with cumulative impact damage is proposed by theoretical derivation with experimental verification and comparative analysis of relevant norms. The conclusions drawn are shown below:

(1) The square of the ultrasonic sound velocity $V_{b}^{2}$ and the stiffness coefficient of the pier $K$ satisfies the relationship of $K=a V_{b}^{2}$;

(2) The calculation results of the ultrasonic damage-containing formula are close to the experimental results, and the relative change rates are all within $10 \%$, which can be considered to be approximately equal;

(3) With the increase of cumulative impact damage of the pier, compared with the normative formula, the impact force peak value of the damage-bearing formula is more consistent with the test curve;

(4) Based on the above conclusions, it can be considered that the collision force formula with damage factor proposed in this paper is able to more accurately reflect the true force of the pier cumulative impact.
Acknowledgements The research described in this paper was sponsored by the Major Project (Natural Science) of Department of Education of Guangdong Province (2014KZDXM064), the Science and Technology Innovation Project of Department of Education of Guangdong Province (2013KJCX0188), and the Civil Engineering Technology Research Center of Guangdong Province. The authors declare that there is no conflict of interest regarding the publication of this paper.

Open Access This article is distributed under the terms of the Creative Commons Attribution 4.0 International License (http://creativeco mmons.org/licenses/by/4.0/), which permits unrestricted use, distribution, and reproduction in any medium, provided you give appropriate credit to the original author(s) and the source, provide a link to the Creative Commons license, and indicate if changes were made.

\section{References}

Aashto, G. S. (1991). Commentary for vessel collision design of highway bridges. Washington, DC: American Association of State Highway and Transportation Officials.

Chen, Z. Q. (2014). Impact property research of the stainless-steel reinforced concrete of bridge piers. Guangdong: Guangdong University of Technology.

Consolazio, G. R., \& Cowan, D. R. (2003). Nonlinear analysis of barge crush behavior and its relationship to impact resistant bridge design. Computers and Structures, 81, 547-557.

Deng, G., Tu, S., Wang, Q., Zhang, X., \& Xuan, F. (2014). Small fatigue crack growth mechanisms of 304 stainless steel under different stress levels. International Journal of Fatigue, 64, 14-21.

Gao, D., Li, X., Wang, Y., \& Fu, R. (2018). Research and application of stainless steel reinforcement are reviewed. Standardization of Engineering Construction, 3, 65-69.

Hu, Z. Q., Gu, Y. N., \& Gao, Z. (2005). Fast evaluation of ship-bridge collision force based on nonlinear numerical simulation. Journal of Marine Science and Application,04, 8-14.

Garcia-Alonso, M. C., Gonzalez, J. A., \& Miranda, J. (2007). Corrosion behavior of innovative stainless steels in mortar. Cement and Concrete Research,37, 1562-1569.

Kachanov, L. M. (1958). Time of the rupture process under creep condition. Izvestiya Akademii Nauk SSSR Otdelenie Tekniches, 8 , 26-31.

Liu, J. C., \& Gu, Y. G. (2001). Research status of ship-bridge collision mechanics and finite element simulation calculation. Sw Chinese User Papers Collection: MSC.

Mohammad, Y., Brian, U., Zhong, T., Alex Remennikov, J. Y., \& Richard, L. (2013). Transverse impact resistance of hollow and concrete filled stainless steel columns. Journal of Constructional Steel Research,82, 177-189.

Pedersen, P. T., Valsgard, S., \& Olsen, D. (1993). Ship impacts: bow collisions. International Journal of Impact Engineering,13, $163-187$.

Qian, J. C., \& Zhou, J. F. (1989). Two damage models of concrete and their applications. The Journal of Hohai University, , 3, 40-47.

Sarno, L. D., Elnashai, A. S., \& Nethercot, D. A. (2003). Seismic performance of stainless steel frames. Journal of Constructional Steel Research, 59, 1289-1319.

Sarno, L. D., Elnashai, A. S., \& Nethercot, D. A. (2006). Seismic retrofitting of steel structures with stainless steel. Journal of Constructional Steel Research,62, 93-104.

Sarno, L. D., Elnashai, A. S., \& Nethercot, D. A. (2008). Seismic response of stainless steel braced frames. Journal of Constructional Steel Research,64, 914-925. 
Sha, Y. Y., \& Hao, H. (2012). Nonlinear finite element analysis of barge collision with a single bridge pier. Engineering Structures, 41 , 63-76.

The Ministry of Railways of PRC. (2005). Basic design code of railway bridges and culverts . TB 10002.1-99.. Beijing: The China Railway Press.

The Ministry of Communications of PRC. (2004). General design code of railway bridges and culverts. JTG,D60-2004(06), 38. Beijing: The China Communications Press.

Vrouwenvelder, A. C. W. M. (1998). Design for ship impact according to eurocode I, ship collision analysis: part 2.7. Rotterdam: A. A. Balkema.

Wang, X. M. (2007). Numerical analysis of ANSYS engineering structure. Beijing: China Communications Press.

Wang, Y., Yuan, H., Shi, Y., Gao, B., \& Dai, G. (2010). A Review of the current applications and research of stainless-steel structures. Steel Structure, 25, 1-12.

Woisin, G. (1976). The collision tests of the GKSS. Jahrb Schiffbautech Gesellsch,70, 465-487.

Yuan, H., Wang, Y., \& Shi, Y. (2011). Preliminary exploration and application prospects of stainless-steel reinforced concrete. Architectural Science, 27, 101-105.

$\mathrm{Xu}, \mathrm{Z}$. L. (2000). The Chinese Society of NDT Ultrasonic testing (pp. 31-41). Beijing: The Machinery Industry Press.

Zhang, G. X., Chen, Z. Q., Lu, J., Xu, S. X., \& Zhou, X. W. (2018). Experimental study on the impact properties of concrete bridge pier reinforced with stainless steel rebar. Journal of testing and evaluation, 46, 1650-1658.

Zhang, G., Xu, S., Xie, H., Zhou, X., \& Wang, Y. (2017). Behavior of stainless steel-reinforced concrete piers under lateral impact loading. Advances in Mechanical Engineering,9, 1-8.

Zhou, X., Gao, Y., Zhang, G., \& Xu, S. (2018). Mechanical properties of equal-strength stainless reinforced replacement piers under lateral impact loading. Advances in Mechanical Engineering,10, $1-13$.

Zhang, P. Y., \& Zhang, X. M. (2001). The relationship between the elastic modulus and elastic wave velocity. The Chinese Journal of Rock Mechanics and Engineering, 6, 785-788.

Zhou, Y. (2008). A pilot experimental study on the low cycle fatigue behavior of stainless steel rebars for earthquake engineering applications. Theses and Dissertations.

Zhang, Z. T., Liu, Y. F. (2011). Concrete plastic damage model in ABAQUS. Building Structure, 41, 229-231.

Publisher's Note Springer Nature remains neutral with regard to jurisdictional claims in published maps and institutional affiliations. 